\title{
Re-examination of the incidence of exercise-induced hypoxaemia in highly trained subjects
}

\author{
Dale D. Brown PhD, Ronald G. Knowlton* PhD, Parviz B. Sanjabit MD and \\ Brad T. Szurgot* MS \\ Department of Health, Physical Education, Recreation and Dance, Illinois State University, Normal, Illinois; \\ *Department of Physical Education, Southern Illinois University, Carbondale, Illinois; tHerrin Hospital, Herrin, \\ Illinois; and Carbondale Clinic and Southern Illinois University School of Medicine, Carbondale, Illinois, USA
}

The purpose of this study was to examine the occurrence of exercise-induced hypoxaemia (EIH) during maximal exercise in highly trained athletes. Eleven trained cyclists (mean(s.d.) age 23(3.5) years; mean(s.d.) $\dot{V o}_{2 \max }$ 66.9(4.8) $\mathrm{ml} \mathrm{kg}^{-1} \mathrm{~min}^{-1}$ ) performed a continuous, multistage $\left(270 \mathrm{kpm} \mathrm{min}^{-1}\right)$ cycle ergometer test to exhaustion. Measurements of arterial oxygen-haemoglobin saturation $\left(\% \mathrm{HbO}_{2}\right)$ were obtained simultaneously at rest, every 2 min during exercise, and at maximum exercise capacity from arterial blood sampling $\left(\% \mathrm{SaO}_{2}\right)$ and ear oximetry $\left(\% \mathrm{SpO}_{2}\right)$. Exercise induced hypoxaemia $\left(\% \mathrm{HbO}_{2} \leqslant 91 \%\right)$ was present in $64 \%$ of the athletes examined when EIH was determined using pulse oximetry, whereas none of the subjects exhibited EIH when $\% \mathrm{HbO}_{2}$ was determined using arterial blood. At rest the values for $\% \mathrm{HbO}_{2}$ were similar with mean(s.d.) $\% \mathrm{SaO}_{2}$ being $97.3(0.6) \%$ and mean(s.d.) $\% \mathrm{SpO}_{2}$ being 96.5(1.6)\%. During exercise, statistically significant differences were found for $\% \mathrm{HbO}_{2}$ between arterial blood and ear oximetry at the 6-min, 8-min, and maximal exercise sampling times (repeated measures analysis of variance, $P<0.05$ ). The results indicate that ear oximetry overestimates the incidence of EIH and underestimates the oxyhaemoglobin saturation in highly trained cyclists during exercise in comparison with those measurements made from arterial blood.

Keywords: Arterial blood, desaturation, exercise, hypoxaemia, trained athletes

It has been postulated that there are two physiological extremes that exist which can limit maximal exercise performance ${ }^{1}$. In the untrained individual, exercise performance becomes limited due to the 'weak links' of the oxygen transport system and oxidative capacity of the muscular system ${ }^{1,2}$. Whereas, in the highly trained individual, the rate limiting step becomes the anatomical and physiological constraints of the respiratory system resulting in 'exercise-induced hypoxaemia' (EIH) ${ }^{1,2}$. Numerous investigations exist reporting arterial oxygen-haemo-

Address for correspondence: Dr Dale D. Brown, Department of Health, Physical Education, Recreation and Dance, Horton Fieldhouse, Room 214, Illinois State University, Normal, Illinois 61761, USA

(C) 1993 Butterworth-Heinemann Ltd 0306-3674/93/030167-04 globin desaturation in highly trained subjects during maximal exercise ${ }^{3-10}$. When using pulse ear oximetry, it has been reported that the incidence of oxygenhaemoglobin desaturation $\left(\% \mathrm{HbO}_{2} \leqslant 91 \%\right)$ during maximal exercise occurs in approximately $50 \%$ of the highly trained athletes examined ${ }^{7}$. It is interesting to note, however, that there has been no scientific study which has examined the occurrence of EIH in highly trained athletes when saturation is determined using invasive procedures (arterial blood) rather than non-invasive ear oximetry analysis. Therefore, it was the purpose of this study to examine the occurrence of arterial oxygen-haemoglobin desaturation during maximal exercise in highly trained athletes.

\section{Materials and methods}

Eleven healthy, trained cyclists of mean(s.d.) age 23.0(3.5) years served as subjects after signing an institutionally approved informed consent. Each subject had a minimum of one year's experience as a licensed (United States Cycling Federation) competitive cyclist. Each subject reported to the laboratory $12 \mathrm{~h}$ after eating for data collection. Baseline ventilatory and metabolic measurements were collected following $20 \mathrm{~min}$ of supine rest. Subsequently, an arterial catheter (Arrow 1.25 inch, 20 Fr) was placed into either the right or left radial artery using the procedure described by Wasserman et al. ${ }^{11}$. The ear probe for the Biox IIa oximeter (Ohmeda, Boulder, Colorado, USA) and interface cables were secured to the subject so as to minimize movement artefact as determined by laboratory experience with the instrumentation. Resting arterial blood samples and ear oximetry readings were obtained simultaneously $15 \mathrm{~min}$ after the catheterization procedures.

\section{Experimental session}

Each subject performed a multistage cycle ergometer aerobic capacity $\left(\dot{V}_{\mathrm{O}_{2}}\right.$ max $)$ test at an initial work rate of $135 \mathrm{~W}$ with a $45 \mathrm{~W}$ increase every minute until exhaustion. A 'true' test of $\dot{V} \mathrm{O}_{2}$ max was considered to be achieved if each subject met two of the following four criteria: a plateau in $\dot{V}_{2}$ with increased exercise workload; a heart rate of $10 \%$ more or less than the 
Table 1. General characteristics of the subjects

\begin{tabular}{|c|c|c|c|c|c|c|c|c|}
\hline $\begin{array}{l}\text { Subject } \\
\text { number }\end{array}$ & $\begin{array}{c}\text { Age } \\
\text { (years) }\end{array}$ & $\begin{array}{l}\text { Height } \\
\text { (cm) }\end{array}$ & $\begin{array}{l}\text { Weight } \\
(\mathrm{kg})\end{array}$ & $\begin{array}{c}\dot{V}_{\mathrm{O}_{2 \max }} \\
\left(m / \mathrm{kg}^{-1} \min ^{-1}\right)\end{array}$ & $R E R$ & $\begin{array}{c}\text { Max } H R \\
\text { (beats } \text { min }^{-1} \text { ) }\end{array}$ & $\begin{array}{l}\operatorname{Max} V E \\
\left(I \min ^{-1}\right)\end{array}$ & $\begin{array}{l}\text { Lactate } \\
\text { (mmol) }\end{array}$ \\
\hline 1 & 28 & 179.1 & 70.0 & -* $^{*}$ & -* $^{*}$ & 191 & 122.0 & 9.3 \\
\hline 2 & 18 & 177.8 & 80.5 & 65.5 & 1.20 & 189 & 190.6 & 10.3 \\
\hline 3 & 28 & 182.9 & 86.4 & 62.4 & 1.12 & 194 & 176.4 & 8.3 \\
\hline 4 & 23 & 182.9 & 77.3 & 72.7 & 1.13 & 184 & 210.7 & 8.5 \\
\hline 5 & 22 & 177.8 & 75.0 & 65.7 & 1.15 & 186 & 166.0 & 9.3 \\
\hline 6 & 22 & 191.0 & 81.8 & 68.0 & 1.24 & 188 & 199.3 & 9.2 \\
\hline 7 & 24 & 180.3 & 84.5 & 61.9 & 1.02 & 195 & 152.5 & 12.2 \\
\hline 8 & 20 & 190.5 & 79.5 & 74.3 & 1.16 & 181 & 150.7 & 9.7 \\
\hline 9 & 20 & 170.2 & 56.8 & 73.4 & 1.15 & 208 & 169.3 & 9.9 \\
\hline 10 & 19 & 180.3 & 70.5 & 66.2 & 1.26 & 192 & 134.1 & 9.5 \\
\hline 11 & 26 & 177.8 & 81.2 & 58.9 & 1.19 & 185 & 173.2 & 6.3 \\
\hline Mean(s.d.) & $22.7(3.5)$ & $181.0(5.9)$ & $76.7(8.4)$ & $66.9(5.2)$ & $1.16(0.07)$ & $190.3(7.3)$ & $167.7(26.9)$ & $9.3(1.4)$ \\
\hline
\end{tabular}

*Data unavailable. RER, respiratory exchange ratio; max $H R$, maximum heart rate; max VE, maximum ventilation

age-predicted maximum; a respiratory exchange ratio greater than 1.0; and a peak whole blood lactate in excess of $8.0 \mathrm{~mm}^{6,7}$. As indicated in Table 1, each subject achieved a 'true' test of maximal aerobic capacity.

Before starting to exercise the cyclists were instructed to remain seated throughout the entire cycle exercise test to avoid extraneous movements to the ear oximeter probe. The Monark cycle ergometer (Varberg, Sweden) was modified with toeclips, cycling seat and handle bars so as to simulate the cyclist's typical racing bicycle. After calibration with standardized reference gases, metabolic and ventilatory data (Quinton Q-Plex, Seattle, Washington, USA) were monitored continuously throughout the cycle ergometer test, using open circuit spirometry. Oxyhaemoglobin saturations for arterial blood $\left(\% \mathrm{SaO}_{2}\right)$ and ear oximetry $\left(\% \mathrm{SpO}_{2}\right)$ were simultaneously obtained every 2 min throughout the cycle exercise test and at maximal exercise capacity. The arterial blood samples were stored in an ice bath and subsequently analysed within $30 \mathrm{~min}$ of the time of withdrawal $^{12}$ for arterial $\mathrm{pH}$, partial pressure of carbon dioxide and oxygen using a Corning 170 Blood Gas Analyzer (Ciba Corning, Medfield, Massachusetts, USA). The arterial oxygen-haemoglobin saturation was calculated automatically by the blood gas analyser. No corrections were made for changes in blood temperature, since it has been shown that short duration, high-intensity exercise produces a minimal increase in core temperature (approximately $\left.0.5^{\circ} \mathrm{C}\right)^{13,14}$ with these temperature changes having an insignificant effect on the determination of arterial oxygen-haemoglobin saturation ${ }^{10}$. Calibration of the blood gas analyser was performed using precision grade reference tank gases and commercially prepared precision grade calibration buffer standards. Blood lactate concentration was determined using a Yellow Springs Lactate Analyzer (Yellow Springs, Ohio, USA) following standardized techniques for calibration.

\section{Statistics}

Analysis of variance for a repeated measures design was used to test for statistical differences, followed by post-hoc analysis (APP-STAT; Statsoft, 1986, Tulsa, Oklahoma, USA). Statistical significance was accepted at a probability of less than 0.05 .

\section{Results}

When using ear oximetry, it has been reported that the incidence of oxyhaemoglobin desaturation (as defined by: $\% \mathrm{HbO}_{2}<91 \%$ ) in highly trained athletes during maximal exercise occurs in approximately $50 \%$ of those examined ${ }^{7}$. Applying that criterion to the results of the present study, seven of 11 subjects $(64 \%)$ would be classified as having arterial oxyhaemoglobin desaturation when desaturation is determined through non-invasive ear oximetry. In contrast, none of the subjects would have been classified as having arterial oxyhaemoglobin desaturation when $\% \mathrm{HbO}_{2}$ was determined using arterial blood sampling.

The $\% \mathrm{SpO}_{2}$ and $\% \mathrm{SaO}_{2}$ values were similar under resting conditions with the mean(s.d.) values being $96.5(1.6) \%$ and $97.3(0.6) \%$, respectively. However, statistical analysis revealed that there was a significant difference in $\% \mathrm{HbO}_{2}$ determinations for arterial blood and ear oximetry at 6-min, 8-min, and maximal exercise sampling times (Table 2 and Figure 1), with these differences becoming prevalent at an exercise intensity of greater than $73 \% \dot{V}_{2 \text { max }}$.

\section{Discussion}

Although previous research using pulse oximetry indicates that approximately $50 \%$ of endurance trained athletes develop $\mathrm{EIH}\left(\% \mathrm{HbO}_{2}<91 \%\right)$, the findings of the present study using arterial blood $\% \mathrm{SaO}_{2}$ failed to find $\mathrm{EIH}$ in any of the endurance trained athletes examined. However, when using pulse ear oximetry, $64 \%$ of the atheletes examined exhibited $\mathrm{EIH}$. The $\% \mathrm{SaO}_{2}$ responses observed in the present study are similar to the data reported by others who have investigated arterial desaturation in highly trained individuals. Dempsey et $\mathrm{al}^{3}$ and Hopkins and McKenzie ${ }^{4}$, using arterial blood sampling, have shown reductions in $\% \mathrm{SaO}_{2}$ from resting values of approximately $5 \%\left(\% \mathrm{SaO}_{2}\right.$ at maximum exercise $=92 \%$ ) during maximal treadmill exercise using highly trained athletes. In this study the 
Incidence of exercise-induced hypoxaemia: D. D. Brown et al.

Table 2. Absolute and change from rest values for percentage oxygen-haemoglobin saturation during the cycle ergometer test

\begin{tabular}{|c|c|c|c|c|c|}
\hline \multirow[b]{2}{*}{ Sampling time (min) } & \multirow[b]{2}{*}{$\begin{array}{l}\text { Oxygen uptake } \\
\left(\% \text { of } \max \dot{V}_{\mathrm{O}_{2}}\right)\end{array}$} & \multicolumn{2}{|c|}{ Absolute value* $\left(\% \mathrm{SO}_{2}\right)$} & \multicolumn{2}{|c|}{ Change from rest ${ }^{*}+\left(\% \mathrm{SO}_{2}\right)$} \\
\hline & & $\begin{array}{c}\text { Ear } \\
\text { oximeter }\end{array}$ & $\begin{array}{l}\text { Arterial blood } \\
\text { samples }\end{array}$ & $\begin{array}{c}\text { Ear } \\
\text { oximeter }\end{array}$ & $\begin{array}{l}\text { Arterial blood } \\
\text { samples }\end{array}$ \\
\hline $\begin{array}{l}\text { Rest } \\
2 \\
4 \\
6 \\
8\end{array}$ & \begin{tabular}{r|}
8.9 \\
37.3 \\
57.1 \\
73.4 \\
89.8
\end{tabular} & $\begin{array}{l}96.5(1.6) \\
95.8(1.3) \\
94.9(1.6) \\
93.6(2.2) \ddagger \\
92.8(2.2) \ddagger\end{array}$ & $\begin{array}{l}97.3(0.6) \\
96.7(0.8) \\
96.2(1.6) \\
95.9(1.5) \\
95.6(1.5)\end{array}$ & $\begin{array}{c}- \\
-0.6(1.6) \\
-1.6(2.3) \\
-2.8(3.0) \\
-3.5(3.3)\end{array}$ & $\begin{array}{c}- \\
-0.6(1.0) \\
-1.1(1.6) \\
-1.3(1.3) \\
-1.7(1.2)\end{array}$ \\
\hline Maximal exercise & 99.6 & $89.9(2.0) \ddagger$ & $95.0(1.7)$ & $-6.6(2.9)$ & $-2.3(1.5)$ \\
\hline
\end{tabular}

*Values are mean(s.d.); + Exercise $\% \mathrm{SO}_{2}$ minus resting $\% \mathrm{SO}_{2} ; \neq$ Statistically different $(P<0.05)$

$\% \mathrm{SaO}_{2}$ decreased by $2.3 \%$, from $97.3 \%$ at rest to $95.0 \%$ during maximal exercise. However, it is interesting to note that none of the studies in the scientific literature that have examined invasively determined arterial blood desaturation in highly trained subjects has found $\% \mathrm{SaO}_{2}$ reductions near the magnitude recorded by non-invasive ear oximetry ${ }^{7,9,15}$. Oxygen-haemoglobin saturation determined from ear oximetry $\left(\% \mathrm{SpO}_{2}\right)$ will typically decrease $8-10 \%$ from rest, with the $\% \mathrm{SpO}_{2}$ values ranging between $84 \%$ and $91 \%{ }^{9,15}$. Similar changes were observed in the present study with the $\% \mathrm{SpO}_{2}$ at maximal exercise being decreased by approximately $7 \%$ from resting conditions.

Previous investigations have shown that the use of ear oximetry is valid and reliable for determining $\% \mathrm{HbO}_{2}$ in subjects who are pulmonary patients, smokers, and 'normal', 'healthy' individuals, at rest, under normoxic and hypoxic conditions ${ }^{16-21}$. A study by Martin et al. ${ }^{22}$ found that pulse, ear and finger oximeters are valid at monitoring arterial oxyhaemoglobin saturations in highly trained athletes during exercise. Yet, in that study, data were presented as the mean difference between $\% \mathrm{SpO}_{2}$ and $\% \mathrm{HbO}_{2}$ (i.e. bias) rather than actual oxyhaemoglobin saturation, therefore it is not possible to relate those findings to the incidence of EIH in highly trained athletes. Additionally, the pulse oximeter used in the validation study by Martin et al. ${ }^{22}$ was the newest model pulse ear oximeter, whereas, an older model ear oximeter was used in the original study which

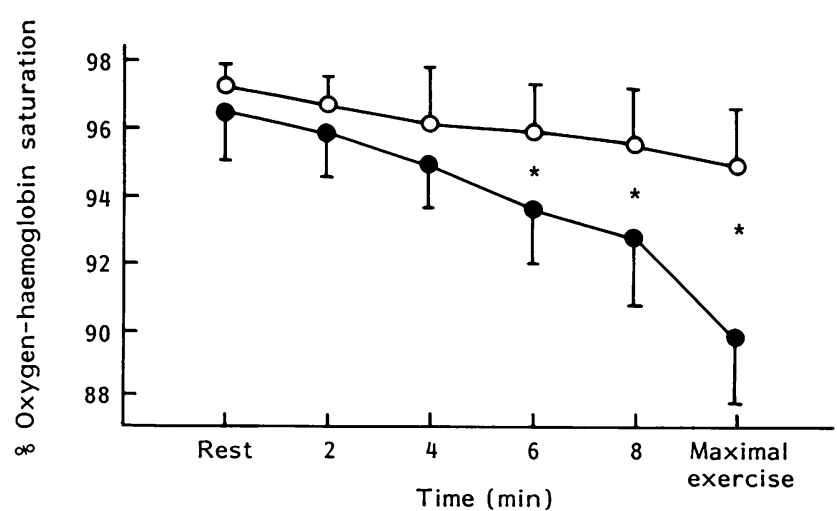

Figure 1. Oxygen-haemoglobin saturation during exercise for arterial blood samples and ear oximetry. $\bigcirc$, arterial blood;, ear oximetry; ${ }^{*}$, significantly different showed the incidence of desaturation to be approximately $50 \%$ of the subjects examined ${ }^{8}$.

The reason for the significant differences in oxyhaemoglobin saturation determinations between ear oximetry and arterial blood at the higher exercise intensities is not known, however, there are a number of possible explanations for the observed differences. It has been speculated that a reduction in ear perfusion during exercise may be a factor in the difference $^{23}$. Although the Biox IIa is equipped with a low perfusion indicator there were no indications from the oximeter that a reduction in perfusion occurred during exercise in any of the subjects in the present study. However, the sensitivity of the low perfusion indicator to respond to perfusion limitations during exercise in highly trained subjects is unknown. Dempsey et al. ${ }^{3}$ showed that in highly trained runners during maximal exercise there is a substantial decrease in mean erythrocyte capillary transit time by comparison with 'average' individuals. The coupled effects of exercise perfusion alterations and an increased rate of blood flow in highly trained subjects during maximal exercise may result in an inability of the oximeter to measure oxygen-haemoglobin saturation of these subjects accurately at high power outputs. Research has indicated that the improper attachment of the oximeter ear probe contributes to the inaccuracy of estimating arterial oxygen-haemoglobin saturation ${ }^{18}$. The extent to which movement artefact contributed to the significantly reduced estimates of $\% \mathrm{HbO}_{2}$ in the ear oximeter is unknown. Even though precautions to prevent extraneous movements of the ear probe were taken as directed by the manufacturer, the exercise requirements may have interacted with the ear oximeter thereby contributing to the resulting difference.

The presence of elevated levels of carboxyhaemoglobin $(\mathrm{HbCO})$ have been shown to alter the ability of oximeters to estimate the oxyhaemoglobin saturation $^{5,20}$. Likewise, calculated oxyhaemoglobin saturations from arterial blood samples may not provide a true reflection of actual oxyhaemoglobin saturation since calculated values do not account for $\mathrm{HbCO}$ binding. Although $\mathrm{HbCO}$ levels were not measured in the present study, there was no reason to expect elevated arterial $\mathrm{HbCO}$, since none of the subjects were smokers. Had an elevated $\mathrm{HbCO}$ been present in these subjects it would be expected that a 
consistent difference in saturation would have been present between the ear oximeter and arterial blood, irrespective of workload.

Although newer pulse oximeter technology is available, numerous scientific investigations are still being completed using the older oximeter technology $7,24,25$. Given the lack of scientific validation studies for the use of older oximeters in exercising highly trained athletes and the significant differences observed for $\% \mathrm{HbO}_{2}$ between non-invasive and invasive methods evidenced in the present study, it would appear that validation of ear oximetry for determining arterial oxygen-haemoglobin saturation in highly trained individuals is strongly warranted. Co-oximeter analysis of arterial blood, which provides a detailed analysis of total haemoglobin and its subfractions (oxyhaemoglobin, methaemoglobin and carboxyhaemoglobin), would be appropriate to ensure the accuracy of reporting the incidence of oxyhaemoglobin desaturation in highly trained athletes during maximal exercise.

This study found that ear oximetry overestimates the incidence of EIH and underestimates the oxyhaemoglobin saturation in highly trained cyclists during exercise in comparison to those measurements made from arterial blood. Although ear oximetry can provide qualitative analysis for arterial blood oxygenation, the validity and accuracy of this technology used with highly trained individuals during maximal exercise remains in question and requires further examination.

\section{Acknowledgements}

Work was done at the Coal Miner's Respiratory Disease Clinic/Cardiopulmonary Laboratory of Herrin Hospital, Herrin, Illinois, USA.

The authors would like to thank Deb Van Tassel and Regina Minton for their technical support in the collection of data for this study. Additional thanks are given to the administration, specifically Joe Hutchcraft, and the staff of the Cardiopulmonary Laboratory and the Respiratory Therapy Department of the Herrin Hospital for their support throughout this project. The authors would also like to extend a note of thanks to Dr John T. Mouw for his assistance in the statistical design for this study.

\section{References}

1 Dempsey JA. Is the lung built for exercise? Med Sci Sports Exerc 1986; 18: 143-55.

2 Dempsey JA, Johnson BD, Saupe KW. Adaptations and limitations in the pulmonary system during exercise. Chest 1990; 97: 81S-87S.
3 Dempsey JA, Hanson PG, Henderson KS. Exercise-induced arterial hypoxaemia in healthy human subjects at sea level. $J$ Physiol (Lond) 1984; 355: 161-75.

4 Hopkins SR, McKenzie DC. Hypoxic ventilatory response and arterial desaturation during heavy work. J Appl Physiol 1989; 67: 1119-24.

5 Powers SK, Dodd S, Freeman J, Ayers GD, Samson H McKnight T. Accuracy of pulse oximetry to estimate $\mathrm{HbO}_{2}$ fraction of total $\mathrm{Hb}$ during exercise. J Appl Physiol 1989; 67: $300-4$.

6 Powers SK, Lawler J, Dempsey JA, Dodd S, Landry G. Effects of incomplete pulmonary gas exchange on $\dot{V}_{\mathrm{O}_{2}, \max } \mathrm{J} \mathrm{Appl}$ Physiol 1989; 66: 2491-5.

7 Powers SK, Dodd S, Lawler J et al. Incidence of exercise induced hypoxemia in elite endurance athletes at sea level. Eur J Appl Physiol 1988; 58: 298-302.

8 Powers SK, Williams J. Exercise-induced hypoxaemia in highly trained athletes. Sports Med 1987; 4: 46-53.

9 Powers SK, Dodd S, Woodyard J, Beadle RE, Church G Haemoglobin saturation during incremental arm and leg exercise. Br J Sports Med 1984; 18: 212-16.

10 Smyth RJ, D'Urzo AD, Slutsky AS, Galko BM, Rebuck AS. Ear oximetry during combined hypoxia and exercise. J Appl Physiol 1986; 60: 716-19.

11 Wasserman K, Hansen JE, Sue DY, Whipp BJ. Principles of Exercise Testing and Interpretation. Philadelphia, USA: Lea and Febiger, 1984.

12 Shapiro BA, Harrison RA, Watson JR. Clinical Applications of Respiratory Gases. Chicago, Illinois, USA: Year Book Medical, 1982.

13 Bergh U, Ekblom B. Physical performance and peak aerobic power output at different body temperatures. J Appl Physiol 1979; 46: 885-9.

14 Saltin B, Gagge AP, Bergh U, Stolwijk JAJ. Body temperatures and sweating during exhaustive exercise. J Appl Physiol 1972; 32: $635-43$.

15 Williams JH, Powers SK, Stuart MK. Hemoglobin desaturation in highly trained athletes during heavy exercise. Med Sci Sports Exerc 1986; 18: 168-73.

16 Escourrou PJL, Delaperche MF, Visseaux A. Reliability of pulse oximetry during exercise in pulmonary patients. Chest 1990; 97: 635-8.

17 Cecil WT, Petterson MT, Lamoonpun S, Rudolph CD Clinical evaluation of the Biox IIA ear oximeter in the critical care environment. Respir Care 1985; 30: 179-83.

18 Reis AL, Farrow JT, Clausen JL. Accuracy of two ear oximeters at rest and during exercise in pulmonary patients. Am Rev Respir Dis 1985; 132: 685-9.

19 Chapman KR, D'Urzo A, Rebuck AS. The accuracy and response characteristics of a simplified ear oximeter. Chest 1983; 83: 860-4.

20 Shippy MB, Petterson MT, Whitman RA, Shivers CR. A clinical evaluation of the BTI Biox II Ear Oximeter. Respir Care 1984; 29: 730-5.

21 Fahey PJ, Gruber S, Siska D, Leach B. Clinical evaluation of a new ear oximeter. Am Rev Respir Dis 1983; 127 (Suppl): 129.

22 Martin D, Powers S, Cicale M, Collop N, Huang D, Criswell D. Validity of pulse oximetry during exercise in elite athletes. J Appl Physiol 1992; 72: 455-8.

23 Hansen JE, Casaburi R. Validity of ear oximetry in clinical exercise testing. Chest 1987; 91: 333-7.

24 Rhodes J, Coast JR, Crouse SF. Arterial desaturation in healthy untrained subjects. Med Sci Sports Exerc 1988; 20 (Suppl): 281.

25 McCusker M, Brilla LR. Exercise induced hypoxemia in female athletes. Med Sci Sports Exerc 1992; 24 (Suppl): 415. 